\title{
Vaginal progesterone in risk reduction of preterm birth in women with short cervix
}

\author{
Shubhi Srivastava*, D. Borgohain
}

Department of Obstetrics and Gynecology, Assam Medical College, Dibrugarh, Assam, India

Received: 18 April 2019

Revised: 13 May 2019

Accepted: 30 May 2019

\section{*Correspondence:}

Dr. Shubhi Srivastava,

E-mail: dr.shubhi.s1@gmail.com

Copyright: (C) the author(s), publisher and licensee Medip Academy. This is an open-access article distributed under the terms of the Creative Commons Attribution Non-Commercial License, which permits unrestricted non-commercial use, distribution, and reproduction in any medium, provided the original work is properly cited.

\begin{abstract}
Background: Preterm birth is a global health problem affecting the neonate, family and country in general. It is the leading cause of perinatal mortality and morbidity. Short cervical length detected on transvaginal ultrasound is the most practical risk factor for prediction of preterm birth. The aim of this study was to determine the efficacy and safety of vaginal progesterone in reducing the rate of preterm birth in women with a short cervix and to determine its effect on neonatal mortality and morbidity.

Methods: The study was carried out in the Department of Obstetrics and Gynaecology at Assam Medical College, Dibrugarh for a period of one year. It included 128 asymptomatic women with a singleton pregnancy and a sonographic short cervix. Women were randomly divided into two groups, one of which was given placebo and the other was given vaginal progesterone and a comparative study was conducted.

Results: It was observed that delivery before 37 weeks of gestation was less frequent in the progesterone group than in the placebo group $(60.94 \%$ vs. $90.63 \%)$. Vaginal progesterone was also associated with a significant reduction in adverse neonatal outcomes like the rate of sepsis $(6.25 \%$ vs. $18.75 \%)$, requirement of ventilator $(12.5 \%$ vs. $26.56 \%)$, admission to NICU (10.94\% vs. $26.56 \%)$ and birth weight $\leq 1.5 \mathrm{~kg}(7.81 \%$ vs. $21.88 \%)$.

Conclusions: Vaginal progesterone reduces the risk of preterm birth and adverse perinatal outcomes in pregnant women without any deleterious effects on the foetus or mother.
\end{abstract}

Keywords: Neonatal morbidity, Preterm birth, Progesterone, Short cervix

\section{INTRODUCTION}

Preterm birth is defined by World Health Organization as the onset of labour before 37 weeks of gestation in a pregnancy beyond 20 weeks of gestation. Every year, an estimated 15 million babies are born preterm worldwide. ${ }^{1}$ Despite advances in perinatal care, Preterm labour and preterm birth is the leading cause of perinatal mortality, which is approximately $10 \%$ of all live births worldwide, which leads to consequent perinatal morbidity and mortality. $^{2}$ One can imagine the agony of life-long suffering of the family because of mental, physical or intellectual impairment resulting from preterm birth. ${ }^{3}$ It can have a far reaching impact on the family, society and even on the economies of the world. ${ }^{4}$ Preterm birth alone accounts for high neonatal morbidity, mortality and healthcare expenses to the society. ${ }^{5}$ Despite these, a standard prenatal care does not include methods to predict or prevent spontaneous preterm birth. ${ }^{6}$

It is seen that success rates in inhibiting labour once the process has started is poor. We can improve neonatal morbidity with administration of corticosteroids and antibiotics, without much success in actually decreasing 
the number of preterm births. Improvements in neonatal care have led to higher rates of survival among very premature infants, but a fruitful effect on the associated mortality and morbidity will be achieved only by better identification of women at high risk for preterm delivery and by application of an effective intervention to prevent this complication. Therefore over the past few decades the attention has shifted towards identifying the patients who are at risk for preterm birth and aggressive preventive programs thereof.

Preterm labour is caused by multiple etiological factors and of the many risk factors identified, short cervical length detected on transvaginal ultrasound is the most plausible, practical and sensitive risk factor for prediction of spontaneous preterm birth. ${ }^{7,8}$ The definition of short cervix has varied in various studies, but most commonly accepted is $\leq 2.5 \mathrm{~cm}$ in the midtrimester of pregnancy.

A clinical intervention to prevent preterm delivery to improve neonatal outcome has become essential to reduce neonatal mortality and morbidity. Micronized progesterone, a naturally occurring steroid hormone, is the most bioavailable form of the class with the fewest side effects. ${ }^{9-11}$ Out of different routes of administration, the vaginal progesterone is one of the safest for mother and fetus, and also well tolerated. Vaginal progesterone is a minimally invasive intervention that is not painful and its benefits clearly outweigh the risks. Considering the facts, the present study was undertaken to evaluate the effect of vaginal progesterone on spontaneous preterm birth in women who were found to have a short cervix at routine mid-trimester screening and also to evaluate its role in reduction of neonatal morbidity and mortality.

\section{METHODS}

The study was carried out in the Department of Obstetrics and Gynaecology at Assam Medical College and Hospital, Dibrugarh for a period of one year from $1^{\text {st }}$ July 2017 to $30^{\text {th }}$ June 2018. It was a hospital based prospective study which included all pregnant women attending the Antenatal Outpatient Department in Assam Medical College and Hospital, Dibrugarh. Approval from the Institutional Ethics Committee was obtained prior to taking up the study.

\section{Inclusion criteria}

- The Singleton gestation

- Gestational age between 19 weeks and 24 weeks

- Transvaginal sonographic cervical length between 10 and $25 \mathrm{~mm}$

- Asymptomatic, i.e. without signs or symptoms of preterm labour.

\section{Exclusion criteria}

- Presence planned cerclage

- Cervical funneling
- Allergic reaction to progesterone

- Current or recent progestogen treatment within the previous 4 weeks

- Chronic medical conditions (e.g. seizure disorders, psychiatric disorders

- Uncontrolled chronic hypertension, congestive heart failure

- Chronic renal failure, uncontrolled diabetes mellitus with end-organ dysfunction

- Active thrombophlebitis or a thromboembolic disorder

- History of hormone-associated thrombophlebitis or thromboembolic disorders

- Active liver dysfunction or disease, known or suspected malignancy of the breast or genital organs)

- Major fetal anomaly or known chromosomal abnormality

- Uterine anatomic malformation (e.g. bicornuate uterus, septate uterus)

- Vaginal bleeding

- Known or suspected clinical chorioamnionitis.

Out of 3034 pregnant women who had gestational age between 19 to 24 weeks, 128 pregnant women who fulfilled the inclusion criteria were chosen and divided equally into two groups and a comparative study was conducted. The pregnant women were randomized such that every odd number women was allotted to Group A and every even number women was put in Group B and so on the pregnant women were allotted in both the groups alternately.

Group A (Control Group): 64 pregnant women who were given placebo

Group B (Progesterone Group): 64 pregnant women who were given vaginal progesterone.

The selected pregnant women were counselled and explained about the study. Upon willingness to participate in the study, they were provided with a written informed consent. Women were given placebo or vaginal progesterone, daily starting from 19 to 24 weeks till 37 weeks, until rupture of membranes or delivery, whichever occurred first. The dose of vaginal progesterone was 100 $\mathrm{mg}$. Women were taught to insert vaginal progesterone or placebo per vaginally at the first visit, thereafter they were instructed to self-administer the drug once daily at bedtime. The women were informed that symptoms related to the administration of drug could include sleepiness, fatigue, headaches, and vaginal irritation, but they were informed that these symptoms are common in pregnancy. They were instructed to return to the hospital every 2 weeks.

At each follow-up visit, compliance of the drug was checked, also she was enquired whether she noted an increase in severity or frequency of these symptoms or had any new symptoms since the beginning of treatment. 
Women who developed preterm labour were treated according to the standard practice of Assam Medical College and hospital. All routine care was carried out as for other antenatal pregnant women. An elaborate history was taken and general physical examination, systemic examination and obstetric examination was done for every pregnant women in the study. All routine investigations and ultrasonography were done according to the standard hospital protocol. Transvaginal sonography was done to determine cervical length. Newborns were attended by paediatrician and were examined thoroughly and any complication was duly noted and managed accordingly.

\section{Statistical analysis}

The data was analysed using SPSS version 17 for Windows Statistical Package. The mean, standard deviation and range of various parameters were computed. The test of significance was calculated using chi square test and differences were regarded as statistically significant with $\mathrm{p}$ value $<0.05$. Microsoft Office Word (2016) and Microsoft Office Excel (2016) were used to generate graphs, tables etc.

\section{RESULTS}

After screening 3034 patients in the study period, 128 patients having short cervix were chosen and divided equally into two groups and a comparative study was conducted. Patients allocated to receive vaginal progesterone (Group B) compared with those allocated to placebo (Group A) had a significantly lower rate of preterm birth before 28 weeks of gestation $(4.69 \%(n=8)$ vs. $12.5 \%(\mathrm{n}=3) ; \mathrm{p}=0.465)$, between 28 to 33 weeks of gestation $(10.94 \% \quad(n=7)$ vs. $25 \% \quad(n=16) ; \mathrm{p}=0.038)$, between 33 to 35 weeks $(18.75 \% \quad(n=12)$ vs. $34.38 \%$ $(n=22) ; p=0.045)$, between 35 to 37 weeks of gestation $(26.56 \%(n=17)$ vs. $18.75 \%(n=12) ; p=0.291) .25$ women $(39.06 \%)$ in Group B vs. 6 women $(9.38 \%)$ in Group A delivered at $\geq 37$ weeks of gestation $(p=0.006)$. Figure 1 illustrates the above findings.

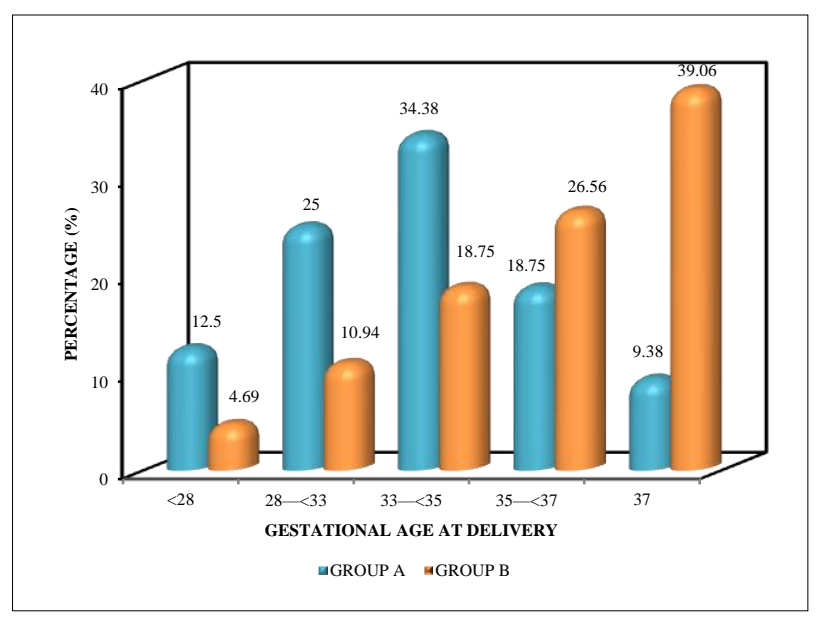

Figure 1: Gestational age at delivery.

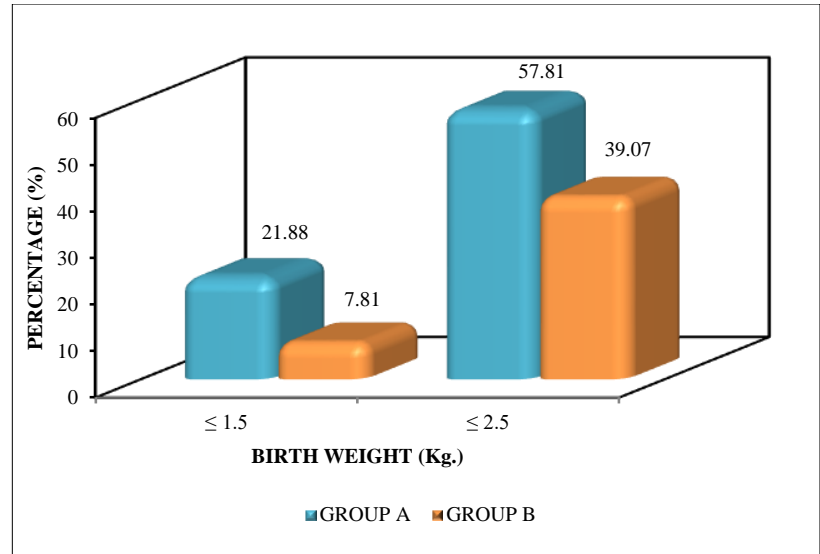

Figure 2: Distribution of neonates according to birth weight.

Figure 2 shows that in Group A, 14 neonates (21.88\%) and in Group B, 5 neonates $(7.81 \%)$ had birth weight $\leq 1.5 \mathrm{~kg}(\mathrm{p}=0.036)$. Thirty-seven neonates $(57.81 \%)$ in Group A and twenty-five neonates (39.07\%) in Group B had birth weight $\leq 2.5 \mathrm{~kg}(\mathrm{p}=0.033)$. The results were statistically significant.

Figure 3 shows that six neonates $(9.38 \%)$ in the Group A and twenty five neonates $(39.06 \%)$ in the Group B were term/post term while $90.63 \%$ and $60.94 \%$ were preterm in Group A and Group B.

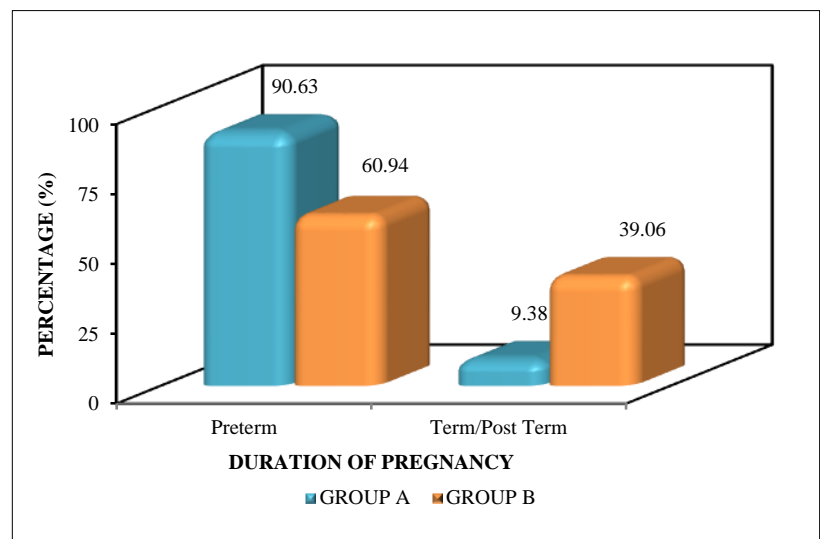

Figure 3: Distribution of neonates according to preterm, term/post term.

This result was statistically highly significant $(\mathrm{p}=$ $0.00008)$.

In terms of neonatal outcome, neonates born to women allocated to receive vaginal progesterone vs. placebo had a significantly lower frequency of adverse outcomes like sepsis $(6.25 \% \quad(n=4)$ vs. $18.75 \% \quad(n=12) ; p=0.032)$. Seventeen neonates $(26.56 \%)$ in Group A, and eight neonates $(12.5 \%)$ in Group B required ventilator ( $\mathrm{p}=$ $0.044)$. Seventeen neonates $(26.56 \%)$ in Group A and seven neonates $(10.94 \%)$ in Group B were admitted to NICU $(p=0.023)$. Other outcomes were seen to be almost equal in both the groups (Table 1). 
Table 1: Distribution of neonates according to fetal outcome.

\begin{tabular}{|llllll|}
\hline Fetal outcome & Group A & & Group B & & p value \\
\hline Respiratory distress syndrome & $\mathbf{n = 6 4}$ & $\mathbf{\%}$ & $\mathbf{n = 6 4}$ & $\mathbf{\%}$ & 0.729 \\
\hline Need of phototherapy & 5 & 7.81 & 4 & 6.25 & 0.129 \\
\hline Bronchopulmonary dysplasia & 17 & 26.56 & 10 & 15.63 & 0.559 \\
\hline Intraventricular haemorrhage & 2 & 3.13 & 1 & 1.56 & 1 \\
\hline Neonatal sepsis & 1 & 1.56 & 1 & 1.56 & 0.032 \\
\hline Requirement of ventilator & 12 & 18.75 & 4 & 6.25 & 0.044 \\
\hline Admission to NICU & 17 & 26.56 & 8 & 12.50 & 0.023 \\
\hline Congenital anomaly & 17 & 26.56 & 7 & 10.94 & 1 \\
\hline Necrotizing enterocolitis & 1 & 1.56 & 1 & 1.56 & 0.559 \\
\hline Retinopathy of prematurity & 1 & 1.56 & 1 & 1.56 & 1.56 \\
\hline
\end{tabular}

Figure 4 shows that still birth was $4.69 \%$ in Group A vs. $3.13 \%$ in Group B. Neonatal death was $12.5 \%$ in Group A vs. $4.69 \%$ in Group B.

Both the results were statistically not significant.

Table 2 shows that there were no important adverse events or side effects in either group. Vaginal discharge was seen in four pregnant women $(6.25 \%)$ in the Group A and in five pregnant women $(7.81 \%)$ in the Group B which was statistically not significant $(\mathrm{p}=0.729)$. Vaginal pruritus was seen in four pregnant women $(6.25 \%)$ in Group A and in three pregnant women $(4.69 \%)$ in Group B which was statistically not significant $(\mathrm{p}=0.697)$.

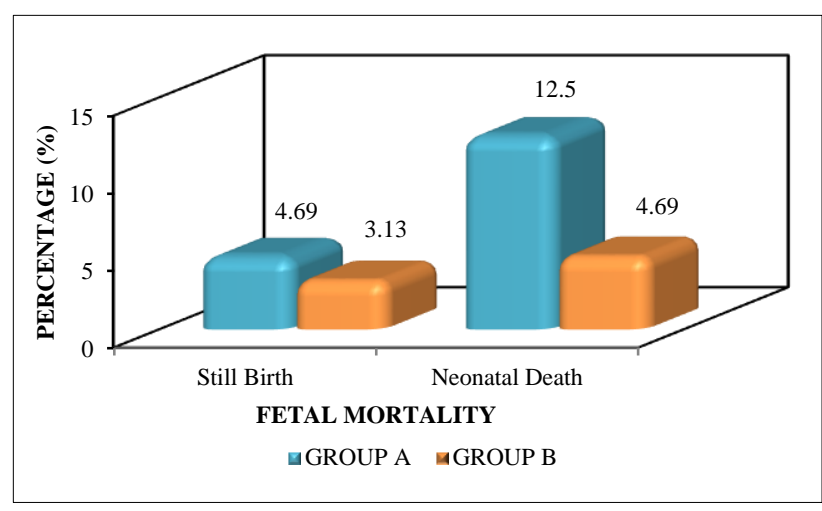

Figure 4: Distribution of neonates according to fetal mortality.

Table 2: Distribution of pregnant women according to maternal adverse events.

\begin{tabular}{|llllll|}
\hline Maternal adverse events & Group A & \multicolumn{3}{c}{ Group B } & p value \\
\hline Vaginal discharge & $\mathbf{n = 6 4}$ & $\mathbf{\%}$ & $\mathbf{n = 6 4}$ & $\mathbf{\%}$ & 0.729 \\
\hline Vaginal pruritus & 4 & 6.25 & 5 & 7.81 & 0.697 \\
\hline Other side effects & 4 & 6.25 & 3 & 4.69 & 0.402 \\
\hline
\end{tabular}

\section{DISCUSSION}

At gestational age $<28$ weeks of gestation the result in the present study was not statistically significant $(\mathrm{p}=0.465)$. However, in the study done by Romero et al, results were found to be statistically significant $(\mathrm{p}=0.04) .{ }^{15}$ This may be due to the large number of cases in their study.

At gestational age between 28 to 33 weeks of gestation, the comparison has been found to be statistically significant $(\mathrm{p}=0.038)$ in the present study. Similar results were seen in two other studies by Anjali et al, and Romero et al, with their results also found to be statistically significant $(\mathrm{p}=0.044$ and $\mathrm{p}=0.003$ respectively). ${ }^{14,15}$
At gestational age between 33 to $<35$ weeks of gestation this comparison has been found to be statistically significant $(\mathrm{p}=0.045)$ in the present study. Similar results were seen in other studies by Fonseca et al, Hassan et al, Anjali et al, and Romero et al, with their results also found to be statistically significant $(\mathrm{p}=0.007$, $\mathrm{p}=0.016, \mathrm{p}=0.044$ and $\mathrm{p}=0.003$ respectively).${ }^{12-15}$

Results in the birth weight of less than $1.5 \mathrm{~kg}$ have been found to be statistically significant in the present study ( $p$ value $=0.036)$. Similar results were seen in other two studies by Hassan et al, and Romero et al, with their results also found to be statistically significant $(\mathrm{p}=0.01$ and $\mathrm{p}=0.004$ respectively). ${ }^{13,15}$ 
Results in the birth weight of less than $2.5 \mathrm{~kg}$ have been found to be statistically significant in the present study (p $=0.033)$. Similar results were seen in study by Romero et al. ${ }^{15}$ However non significant results were seen in other studies done by Fonseca et al, Hassan et al, and Anjali et al. ${ }^{12-14}$

In terms of neonatal sepsis and requirement of ventilator the results have been found to be statistically significant in present study similar to the study by Fonseca et al with their results also found to be statistically significant. ${ }^{6}$

In terms of admission to NICU, similar results were seen in other two studies mentioned by Fonseca et al, and Romero et al, with their results also found to be statistically significant $(p=0.05$ and $p=0.003$ respectively). ${ }^{12,15}$ However non significant results were seen in study done by Anjali et al. ${ }^{14}$

There was no statistical significance in both the groups in terms of maternal adverse events like vaginal discharge, vaginal pruritus and other side effects. Similar result was seen in the study done by Romero et al, where $11 \%$ women in Control Group and $12 \%$ women in the Progesterone Group had maternal adverse events which was comparable to our results. ${ }^{15}$

\section{CONCLUSION}

Preterm birth is one of the most important challenges to modern obstetrics. Preventing preterm labour will result in insurmountable benefits not only to that neonate, but also to that family, and the society financially as well as emotionally and intellectually and lighten the burden of chronic diseases.

Spontaneous preterm birth is a syndrome caused by multiple etiologies, one of which is a decline in progesterone action, which induces cervical ripening. A short cervix $(\leq 2.5 \mathrm{~cm})$ in the midtrimester of pregnancy, is a powerful risk factor for spontaneous preterm birth and has a high predictive accuracy for spontaneous preterm birth. Multiple prospective studies have consistently shown benefits of vaginal progesterone in decreasing spontaneous preterm birth in women with asymptomatic midtrimester short cervix.

It was observed in the present study that vaginal progesterone had a significant reduction in preterm birth. Also, it improved neonatal outcome by significant decrease in the rate of sepsis of newborn and requirement of ventilator. There was significant decrease in the low birthweight $(<2500 \mathrm{~g})$ babies, very low birthweight ( $<1500 \mathrm{~g}$ ) babies, and NICU admission. Use of vaginal progesterone for women with a short cervix is safe for mother and fetus, and also well tolerated.

Funding: No funding sources

Conflict of interest: None declared
Ethical approval: The study was approved by the Institutional Ethics Committee

\section{REFERENCES}

1. Liu L, Oza S, Hogan D, Chu Y, Perin J, Zhu J, et al. Global, regional, and national causes of under-5 mortality in 2000-15: an updated systematic analysis with implications for the Sustainable Development Goals. Lancet. 2016;388(10063):3027-35.

2. Manuck TA, Rice MM, Bailit JL. Preterm neonatal morbidity and mortality by gestational age: a contemporary cohort. Am J Obstet Gynecol. 2016;215:103.e1-103.e14.

3. Smith DD, Miller R, Gyamfi-Bannerman C. Risk of cerebral palsy by gestational age epoch. Am J Obstet Gynecol. 2016;214:S180.

4. Marlow N, Wolke D, Bracewell MA, Samara M. Neurologic and developmental disability at six years of age after extremely preterm birth. N Engl J Med. 2005;352:9-19.

5. Luu TM, Katz SL, Leeson P, Thébaud B, Nuyt AM. Preterm birth: risk factor for early-onset chronic diseases. CMAJ. Canadian Med Assoc J. 2016;188(10):736-40.

6. Lockwood CJ, Kuczynski E. Risk stratification and pathological mechanisms in preterm delivery. Paediatr Perinat Epidemiol. 2001;15(suppl S2):7889.

7. Iams JD, Goldenberg RL, Meis PJ. The length of the cervix and the risk of spontaneous premature delivery. N Engl J Med. 1996;334:567-72.

8. To MS, Skentou CA, Royston P, Yu CK, Nicolaides KH. Prediction of patient-specific risk of early preterm delivery using maternal history and sonographic measurement of cervical length: a population based prospective study. Ultrasound Obstet Gynecol. 2006;27:362-7.

9. da Fonseca EB, Bittar RE, Carvalho MH, Zugaib M. Prophylactic administration of progesterone by vaginal suppository to reduce the incidence of spontaneous preterm birth in women at increased risk: a randomized placebo-controlled double-blind study. Am J Obstet Gynecol. 2003;188:419-24.

10. Dodd JM, Flenady V, Cincotta R, Crowther CA. Prenatal administration of progesterone for preventing preterm birth. Cochrane Database Syst Rev. 2006;1:CD004947.

11. $\mathrm{Xu} \mathrm{H}$, Gonzalez JM, Ofori E, Elovitz MA. Preventing cervical ripening: the primary mechanism by which progestational agents prevent preterm birth? Am J Obstet Gynecol. 2008;198:314.e1-8.

12. Fonseca EB, Celik E, Parra M, Singh M, Nicolaides KH. Progesterone and the risk of preterm birth among women with a short cervix. N Engl J Med. 2007;357:462-9.

13. Hassan SS, Romero R, Vidyadhari D. Vaginal progesterone reduces the rate of preterm birth in women with a sonographic short cervix: a multicenter, randomized, double-blind, placebo- 
controlled trial. Ultrasound Obst Gynecol. 2011;38:18-31.

14. Gupta A, Sharan S, Sen J. Vaginal progesterone in asymptomatic women with short cervical length on ultrasound: is it beneficial? J Fetal Med. 2015;2(2):69-73.

15. Roberto R, Agustin CA, Eduardo Da F, O'Brien JM, Cetingoz E, Creasy GW, et al. Vaginal progesterone for preventing preterm birth and adverse perinatal outcomes in singleton gestations with a short cervix: a meta-analysis of individual patient data. Am J Obst Gynecol. 2018;2:161-80.

Cite this article as: Srivastava $\mathrm{S}$, Borgohain D. Vaginal progesterone in risk reduction of preterm birth in women with short cervix. Int J Reprod Contracept Obstet Gynecol 2019;8:2695-700. 